\title{
IMPURITY PHASES IN BERYLLIUM OXIDE CERAMIC
}

\author{
S. K. Turnaev, ${ }^{1}$ G. D. Bitsoev, ${ }^{2}$ G. M. Kil'govatov, ${ }^{1}$ and V. S. Kiiko ${ }^{3}$
}

Translated from Novye Ogneupory, No. 10, pp. 48 - 55, October, 2012.

Original article submitted April 10, 2012.

An x-ray spectrographic method with an electron probe and a scanning electron microscope are used to study industrial ceramic specimen surface composition, distinguished by presence of a different color for both the main part, and impurity phases. $\mathrm{BeO}$-ceramic specimens, having a visually differing color, are conditionally separated into three types. In reflected electron microphotographs impurities are distinguished qualitatively with respect to electrical conductivity. Iron impurity is invariably present within the composition of electrically conducting phases and inclusions. Apart from iron, all impurity phases contain carbon, aluminum, silicon, and calcium, and within individual phases there are admixtures of manganese, magnesium, chromium, potassium, sodium, zinc, phosphorus, and chlorine, which may be introduced into $\mathrm{BeO}$-ceramic during production and sintering in repeatedly used industrial furnaces from linings and residual atmosphere.

Keywords: BeO-ceramic, impurity phases, inclusions, microstructure, color of impurity phases in reflected electrons, specimens, electrically conducting phases, phase composition.

Ceramics based on beryllium oxide due to its high thermal conductivity (reaching $330 \mathrm{~W} /(\mathrm{m} \cdot \mathrm{K})$ ), thermal, chemi$\mathrm{cal}$, and radiation resistance, high dielectric and strength properties, are used extensively in special metallurgy, nuclear, space, electron, and laser technology $[1-6]$. It is a transparent material for vacuum ultraviolet, $\mathrm{x}$-ray, and UHF radiation. Beryllium ceramic is a most promising material for quantum electronics, where it is used in powerful ion and molecular gas optical quantum generators as dielectric tubes of optical resonators and hollow dielectric waveguides in waveguide gas discharge lasers of the central IR-range $(1,3$, 5]. Light-transmitting $\mathrm{BeO}$-ceramic is considered as a new material for creating solid-state lasers in the ultraviolet region of the spectrum [7]. Recently BeO-ceramic has been used as a material for high-voltage insulators in chambers with magnetic compression in order to obtain high-temperature magnetized hydrogen plasma, within which there is thermonuclear reaction [1]. It is well known that impurity atoms have a considerable effect on electrical and physicochemical properties of beryllium oxide [8]. Impurities may change thermal conductivity, dielectric permittivity, and optical properties, and affect microstructure morphology, rate of $\mathrm{BeO}$ crystal growth, and ceramic operating properties. After

1 TOO KazMeshizProm, Ust'-Kamenogorsk, Kazakhstan Republic.

2 West Kazakhstan D. Serikbaev Technical University, Ust'-Kamenogorsk, Kazakhstan Republic.

3 FGAOU VPO Ural Federal University, Ekaterinburg, Russia. modification with certain impurities BeO-ceramic may be used as effective scintillators, working bodies in thermoluminescent, exoemission, and electron paramagnetic resonance dosimeters of ionizing radiation [1].

Impurities connected with beryllium oxide may be separated into several groups $[1,2]$ :

- anionic, affecting object density during sintering (fluorides, sulphates, and phosphates);

isomorphic substituting beryllium ions in a cation sub-lattice $\left(\mathrm{Li}^{+}, \mathrm{B}^{3+}, \mathrm{Zn}^{2+}, \mathrm{Al}^{3+}\right)$ or arranged predominantly in octahedral internodes of $\mathrm{BeO}\left(\mathrm{Na}^{+}\right)$;

- covering ceramic objects and located along $\mathrm{BeO}$ microcrystal boundaries and pores, and also forming at a surface and within ceramic impurity inclusions of oxide phases and microstructures $\left(\mathrm{BeAlO}_{4}, \mathrm{Al}_{2} \mathrm{O}_{3}, \mathrm{Fe}_{2} \mathrm{O}_{3}, \mathrm{Fe}_{3} \mathrm{C}, \mathrm{Cr}_{2} \mathrm{O}_{3}\right.$, $\mathrm{CuO}, \mathrm{CaO}$, and $\mathrm{SiO}$ ), affecting ceramic and electrophysical properties;

- having an effect on thermomechanical, optical, and dielectric properties of glass and eutectic components $\left(\mathrm{Al}_{2} \mathrm{O}_{3}\right.$, $\mathrm{Fe}_{2} \mathrm{O}_{3}, \mathrm{Cr}_{2} \mathrm{O}_{3}, \mathrm{CaO}, \mathrm{MgO}$, and $\mathrm{SiO}$ );

- reducing nuclear efficiency (elements, $\mathrm{Co}, \mathrm{Li}, \mathrm{Ag}, \mathrm{B}$, and $\mathrm{Cd}$ ).

Quantum-chemical methods for calculation within the scope a model of dilute solid solutions $\mathrm{Be}_{x} \mathrm{M}_{y} \mathrm{O}(x \gg y)$ has be used by us the study the effect of impurities of $3 d$-metals ( $\mathrm{Sc}, \mathrm{Ti}, \mathrm{V}, \mathrm{Cr}, \mathrm{Fe}, \mathrm{Co}, \mathrm{Ni}, \mathrm{Mn}, \mathrm{Cu}, \mathrm{Zn}$ ) and other impurities on electron and magnetic properties of $\mathrm{BeO}$. In the course of 
research it has been detected that doping of a Be sub-lattice with different atoms of $3 d$-metals in $\mathrm{BeO}$ leads to preparation of a rich spectrum of nonmagnetic materials, magnetic semi-metals, magnetic semiconductors, as new materials for spin electronics $[9,10]$.

This broad spectrum of BeO-ceramic functional properties, containing different impurities, gives rise in objects made from it of a series of specific properties, which may be changed in relation to presence of impurity phases within a ceramic, leading to occurrence of colored regions. Colored regions sometimes entirely cover the surface of objects, and also are located within them. For BeO-ceramic objects there is typically occurrence of coloring in the visible range of the spectrum, having white and somewhat yellowish shade, and also gray and dark-gray color. Previously $[11,12]$ by means of x-ray photoelectron spectroscopy (XPES) we have studied the surface composition of commercial BeO-ceramic with different density and visual colors of white, grey and dark colors. It has been established that within a BeO-ceramic surface layer there are impurities of different elements. Electron paramagnetic resonance (EPR), optical absorption, magnetostatics and nuclear gamma-resonance (NGR), have been used to study different iron phases in $\mathrm{BeO}$-ceramic having white, gray, and dark color [13 - 16].

This work is a logical continuity of studies carried out previously for impurity phases and inclusions, and also colored areas arising in $\mathrm{BeO}$-ceramic specimens during its industrial manufacture $[1,11-16]$.

Sintered BeO-ceramic in the from of plates, having different colored areas and inclusions, have been studied by means of electron scanning microscope JSM-639 DM with a microanalyzer attachment INSA Energy, Specimens of ceramic objects from mixed $\mathrm{BeO}$ powders, consisting of low(50 wt.\%) and highly-fired (50 wt.\%) powders were prepared in the enterprise TOO KazMetiz-Prom (Ust'-Kamenogorsk, Kazakhstan republic) [4]. Highly-fired $\mathrm{BeO}$ powder was prepared by grinding scrap ceramic objects and leaching impurities, added to it during crushing and grinding.

The original $\mathrm{BeO}$ powder and ceramic based on it contained impurities remaining in the powder during production processes, and ceramic sintering (Table 1) [4].

Individual areas of ceramic specimens were studied with the most often encountered defects with respect to color of spots, i.e., from dark gray to bright-white in the main field of a plate, having a visually different color. Three types of specimen were selected with the most typical defects arising during production of $\mathrm{BeO}$-ceramic objects. Microsections were prepared from the selected specimens.

For defects of the first type there is typically presence at the surface of light BeO-ceramic of dark spots. An electron image is shown in Fig. 1 for a typical defect for BeO-ceramic of the first type. Observation of colored areas of BeO-ceramic in reflected electrons showed that inclusions at a ceramic surface are distinguished with respect to electrical conductivity (see Figs. 1 and 2). The most electrically conducting inclusions in microphotographs have a white color (see

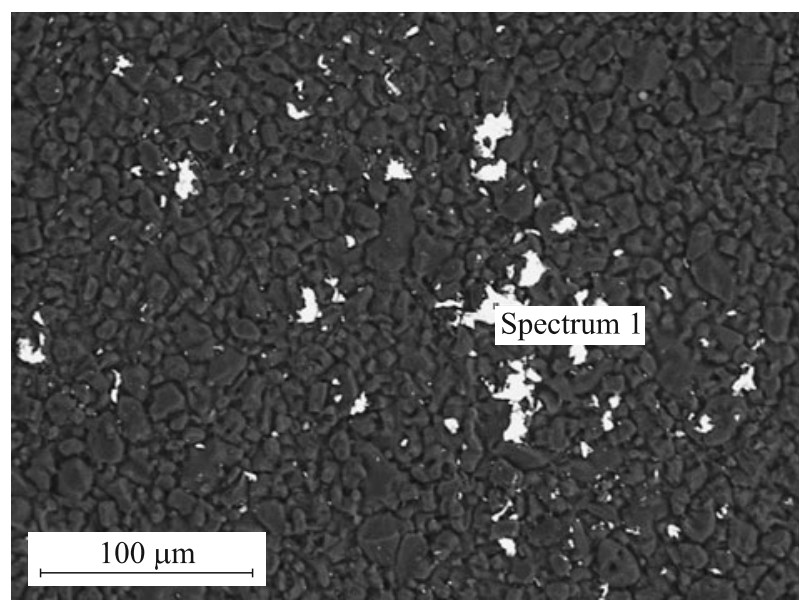

Fig. 1. Impurity phase inclusions exhibiting maximum electrical conductivity in $\mathrm{BeO}$-ceramic of the first type in reflected electrons.

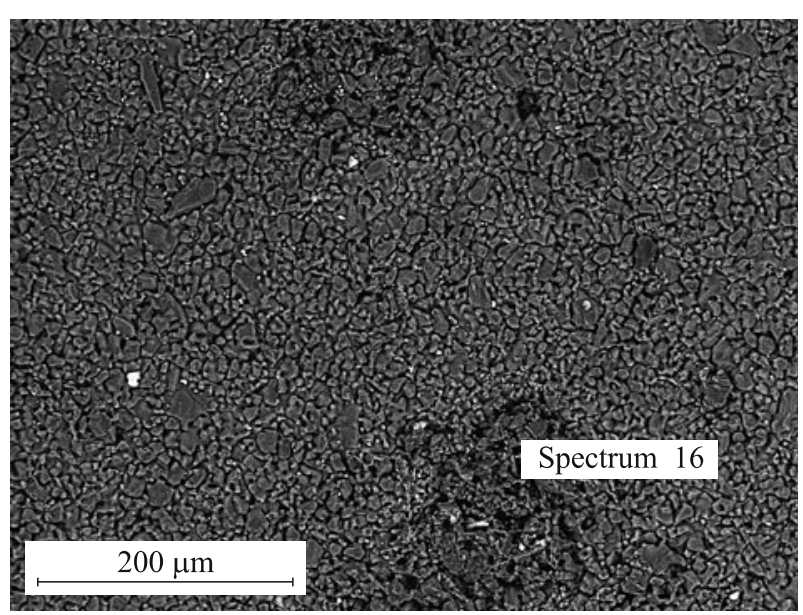

Fig. 2. Impurity phase inclusions in BeO-ceramic of the first type exhibiting maximum electrical conductivity, dark - minimum.

TABLE 1. Average impurity content, wt.\%, in Original Powder and Sintered ceramic

\begin{tabular}{lcc}
\hline \multicolumn{1}{c}{ Impurity } & Original $\mathrm{BeO}$ powder & BeO-ceramic \\
\hline $\mathrm{SiO}_{2}$ & 0.008 & 0.019 \\
$\mathrm{Fe}_{2} \mathrm{O}_{3}$ & 0.032 & 0.057 \\
$\mathrm{Al}_{2} \mathrm{O}_{3}$ & 0.019 & 0.034 \\
$\mathrm{Cr}_{2} \mathrm{O}_{3}$ & 0.002 & 0.003 \\
$\mathrm{Ni}_{2} \mathrm{O}_{3}$ & 0.004 & 0.001 \\
$\mathrm{CaO}$ & 0.011 & 0.012 \\
$\mathrm{MgO}$ & 0.013 & 0.004 \\
$\mathrm{ZnO}$ & 0.025 & 0.017 \\
$\mathrm{Total}$ impurities & 0.114 & 0.147 \\
\hline
\end{tabular}

Fig. 1). Results are provided in Table 2 for a study of the composition of impurity phases having a white color in sec- 
ondary electrons. As is well known, the contrast of images (in reflected electrons) of impurity phases in $\mathrm{BeO}$-ceramic is connected primarily with the effective atomic number $Z_{\text {eff }}$ of ceramic and impurity phases. $Z_{\text {eff }}$ of $\mathrm{BeO}$-ceramic is 7.13 ,

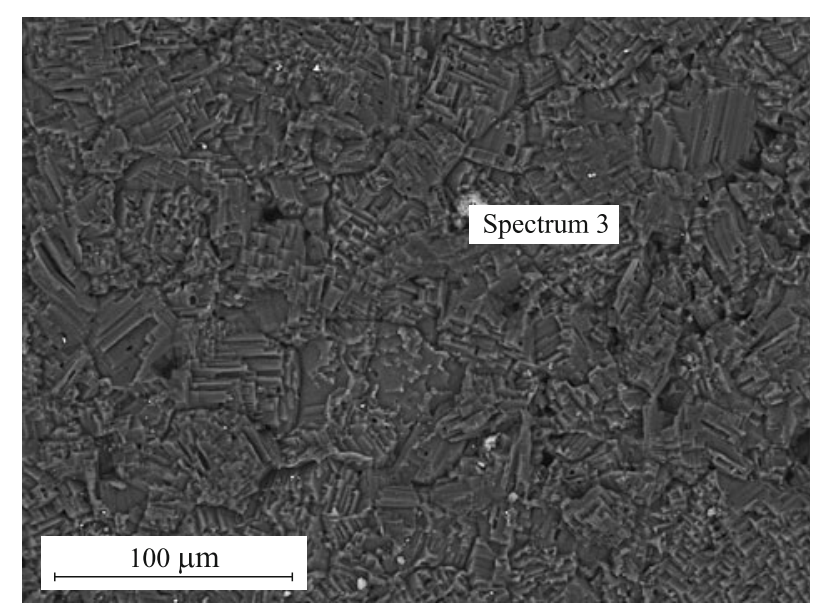

Fig. 3. Impurity phase inclusions having increased electrical conductivity in $\mathrm{BeO}$-ceramic of the second type in reflected electrons.

TABLE 2. Impurity Composition and Content in First Type BeO-Ceramic Impurity Phases Exhibiting Maximum Electrical Conductivity

\begin{tabular}{lcc}
\hline \multirow{2}{*}{ Impurity element } & \multicolumn{2}{c}{ Impurity element content } \\
\cline { 2 - 3 } & wt.\% & at.\% \\
\hline $\mathrm{C}$ & 2.08 & 6.26 \\
$\mathrm{O}$ & 18.48 & 41.72 \\
$\mathrm{Si}$ & 0.23 & 0.42 \\
$\mathrm{Cr}$ & 9.42 & 6.54 \\
$\mathrm{Mn}$ & 0.63 & 0.42 \\
$\mathrm{Fe}$ & 69.06 & 44.65 \\
Total & 100.00 & - \\
\hline
\end{tabular}

TABLE 3. Impurity Composition and Content in First Type BeO-Ceramic Impurity Phases Exhibiting Low Electrical Conductivity

\begin{tabular}{lcc}
\hline \multirow{2}{*}{ Impurity element } & \multicolumn{2}{c}{ Impurity element content } \\
\cline { 2 - 3 } & wt.\% & at.\% \\
\hline $\mathrm{C}$ & 2.19 & 2.91 \\
$\mathrm{O}$ & 96.56 & 96.43 \\
$\mathrm{Al}$ & 0.42 & 0.25 \\
$\mathrm{Si}$ & 0.43 & 0.25 \\
$\mathrm{Ca}$ & 0.41 & 0.16 \\
Total & 100.00 & - \\
\hline
\end{tabular}

but it not possible to determine the value of $Z_{\text {eff }}$ for impurity phases. Presence within BeO-ceramic of impurity phase inclusions having in reflected electrons a white color, is confirmed by data in $[17,18]$, within which introduction in ceramic of strongly reducing and therefore electrically conducting titanium oxide led to coloring of titanium oxide microcrystals. By analogy with this we assume that the light color of impurity phases and inclusions in reflected electrons in this case is due to their increased electrical conductivity. Impurity elements in all specimens are specified with respect to $\mathrm{K}_{\alpha}$ of electron levels in their radiation.

Also presented in Fig. 2 is the structure of a BeO-ceramic specimens of the first type in reflected electrons. The surface of BeO-ceramic, where there are no impurity phases, in reflected electrons is in the from of gray uniform surface, exhibiting low electrical conductivity. As is well known, $\mathrm{BeO}$ is a good electrical insulator with a large broad forbidden gap $(\sim 10.8 \mathrm{eV})$. In a microphotograph (see Fig. 2 ) shown in reflected electrons is an area of a dark zone of impurity phases in $\mathrm{BeO}$-ceramic, whose elemental composition is provided in Table 3.

Numerous studies of the composition of impurity phases in a $\mathrm{BeO}$-ceramic surface of the first type, exhibiting low electrical conductivity in reflected electrons (whose microphotographs are not given) have also shown (Table 4) that within the composition of impurities, apart carbon, aluminum, and silicon, iron impurity is present.

For specimens of $\mathrm{BeO}$-ceramic of the second type there is typically presence of dark spots in gray ceramic. In reflected electrons, the same as in specimens of the first type, there are impurity phases distinguished from the main $\mathrm{BeO}$ phase with respect to electrical conductivity and therefore having light or dark color (Fig. 3).

As follows from spectral measurements of BeO-ceramic of the second type, visually having a basic gray color with inclusions of impurity phase of white color in reflected electrons, they contain impurities, in which the maximum amount is for carbon, aluminum, and silicon (Table 5). The iron impurity content in this case is much less than in specimens of white color (in reflected electrons) in the first type

TABLE 4. Impurity Composition and Content in First Type BeOCeramic Impurity Phases Exhibiting Low Electrical Conductivity

\begin{tabular}{|c|c|c|}
\hline \multirow{2}{*}{ Impurity element } & \multicolumn{2}{|c|}{ Impurity element content } \\
\hline & wt. $\%$ & at. $\%$ \\
\hline $\mathrm{C}$ & Not determined & \\
\hline $\mathrm{O}$ & 64.48 & 77.19 \\
\hline $\mathrm{Al}$ & 12.14 & 8.62 \\
\hline $\mathrm{Si}$ & 15.74 & 10.73 \\
\hline $\mathrm{K}$ & 5.69 & 2.79 \\
\hline $\mathrm{Fe}$ & 1.94 & 0.67 \\
\hline Total & 100.00 & - \\
\hline
\end{tabular}




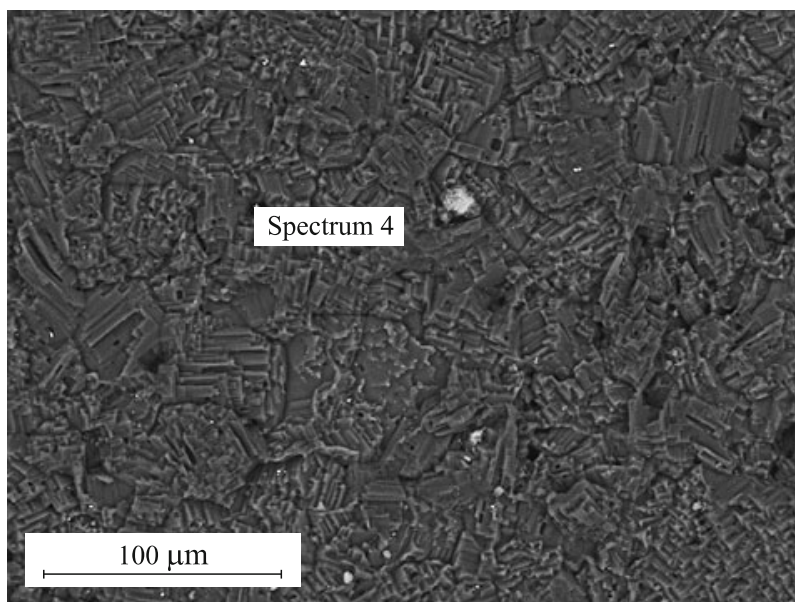

Fig. 4. Impurity phase exhibiting low electrical conductivity in $\mathrm{BeO}$-ceramic of the second type.

(see Fig. 1, Table 2). At the surface there is also presence of potassium, zinc, and chlorine impurities. Presence of chlorine impurity has been observed by us previously $[11,12]$ in studying a ceramic surface by the XPES method. In our opinion the chlorine impurity is captured by a $\mathrm{BeO}$ powder surface during chemical purification in a hydrochloric acid solution in different stages of the production process. It has been established that chlorine is held stably at the surface of $\mathrm{BeO}$-ceramic even after sintering in a rough vacuum and placed in a high vacuum to $10^{-10} \mathrm{~mm} \mathrm{Hg}$ [11].

Composition has also been determined for $\mathrm{BeO}$-ceramic of the second type having a dark color in reflected electrons (Fig. 4, Table 6). A study of the elementary composition of a $\mathrm{BeO}$-ceramic surface of the second type over a considerable

TABLE 5. Impurity Composition and Content in First Type BeOCeramic Impurity Phases Exhibiting Maximum Electrical Conductivity

\begin{tabular}{lcc}
\hline \multirow{2}{*}{ Impurity element } & \multicolumn{2}{c}{ Impurity element content } \\
\cline { 2 - 3 } & wt.\% & at.\% \\
\hline $\mathrm{C}$ & 8.65 & 12.57 \\
$\mathrm{O}$ & 65.61 & 71.55 \\
$\mathrm{Na}$ & 0.31 & 0.24 \\
$\mathrm{Mg}$ & 0.73 & 0.52 \\
$\mathrm{Al}$ & 9.84 & 6.36 \\
$\mathrm{Si}$ & 12.66 & 7.87 \\
$\mathrm{~S}$ & 0.26 & 0.14 \\
$\mathrm{Cl}$ & 0.11 & 0.05 \\
$\mathrm{~K}$ & 1.13 & 0.50 \\
$\mathrm{Zn}$ & 0.43 & 0.12 \\
$\mathrm{Fe}$ & 0.27 & 0.08 \\
Total & 100.00 & - \\
\hline
\end{tabular}

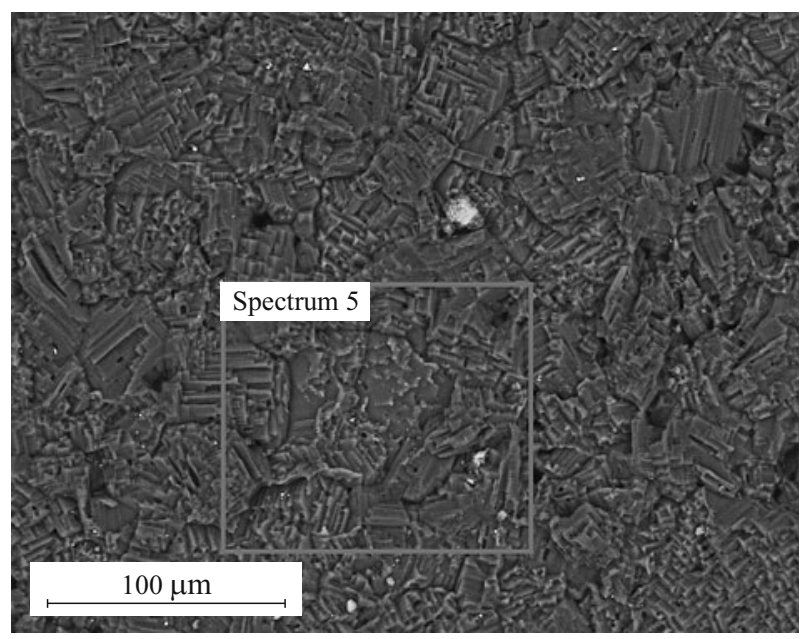

Fig. 5. Area of second type ceramic within which impurity phase elemental composition was studied.

area showed that the surface of gray ceramic with inclusions of dark spots predominantly consists of carbon, sodium, aluminum, and silicon (see Table 7, Fig. 5).

As studies have shown, ceramic of the second type having a visually gray color with inclusions of dark spots, has an increased content of carbon, magnesium, aluminum, and silicon impurities. Probably these impurities are in a partly reduced condition or forming some compounds that it is impossible to determine by means of this method, and give rise to the gray color of a $\mathrm{BeO}$-ceramic surface.

Specimens of BeO-ceramic of the third type had visually light spots on gray ceramic. As in specimens of the first and second types, impurities in specimens of the third type in reflected electrons also have a light color, and this is confirmed by their increased electrical conductivity (Fig. 6). The composition of impurities in the area of surface with an electrically conducting impurity phase is provided in Table 8 . The composition of the impurity in an area of gray ceramic (Fig. 7) not exhibiting increased electrical conductivity, is provided in Table 9.

Repeated study of the composition of impurities in the surface of BeO-ceramic of the third type in areas where in re-

TABLE 6. Impurity Composition and Content in Second Type BeO-Ceramic Impurity Phases Exhibiting Low Electrical Conductivity

\begin{tabular}{lcc}
\hline \multirow{2}{*}{ Impurity element } & \multicolumn{2}{c}{ Impurity element content } \\
\cline { 2 - 3 } & wt.\% & at.\% \\
\hline $\mathrm{C}$ & 4.56 & 6.13 \\
$\mathrm{O}$ & 89.32 & 90.17 \\
$\mathrm{Mg}$ & 0.58 & 0.38 \\
$\mathrm{Al}$ & 5.55 & 3.32 \\
Total & 100.00 & - \\
\hline
\end{tabular}




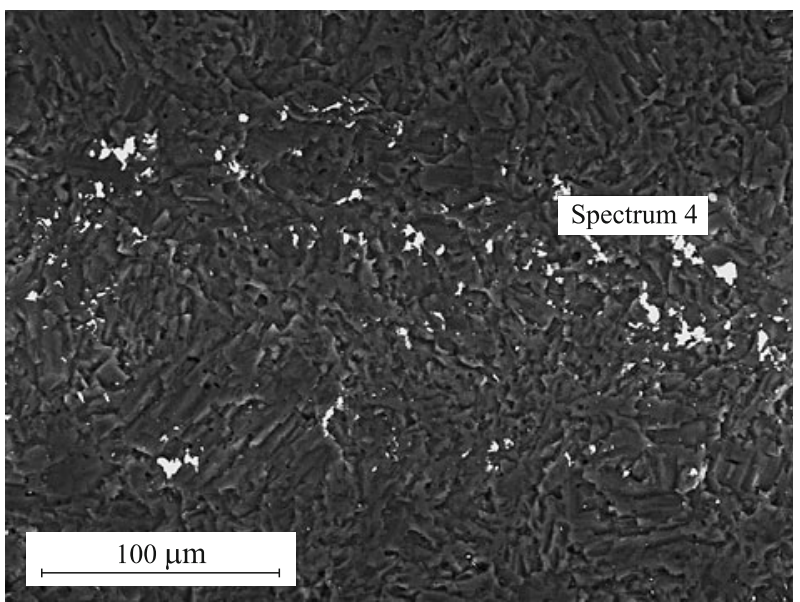

Fig. 6. Impurity phase inclusions exhibiting increased electrical conductivity in third type BeO-ceramic.

flected electrons colored impurity phases are not observed, showed that impurities in the surface of ceramic consist as a rule of carbon, calcium, and aluminum, probably in the form of oxide $\mathrm{Al}_{2} \mathrm{O}_{3}$ having a light color. Presence of an increased amount of aluminum oxide in impurity phases in our opinion leads to occurrence of impurity inclusions having visually a white color in gray ceramic.

Numerous studies of $\mathrm{BeO}$ powder chemical composition and different batches sintered industrial $\mathrm{BeO}$-ceramic demonstrate presence within its composition predominantly of impurities $\mathrm{Fe}, \mathrm{Si}, \mathrm{Al}$, and $\mathrm{Ca}[1,2]$. Due to low isomorphic capacity of typical impurities, $\mathrm{Li}, \mathrm{B}, \mathrm{Al}, \mathrm{Zn}, \mathrm{Mg}, \mathrm{Si}$ are within the $\mathrm{BeO}$ crystal lattice at the level of background values of $10^{-4}-10^{-3} \mathrm{wt} . \%$. Impurities are added to ceramic together with the original raw material in the process of preparing $\mathrm{BeO}$ powder or absorbed from a furnace gas phase during sintering of objects. With an impurity content exceeding background values, the majority of them are not isomorphically within the $\mathrm{BeO}$ crystal lattice. Impurities are arranged at the surface or in the surface area of $\mathrm{BeO}$ microcrystals, or at the surface of pores forming surface microstructures or phases. With an increased content impurities may not only

TABLE 7. Impurity Composition and Content in Second Type BeO-Ceramic Surface, Separated in Fig. 5 in the Form of a Square

\begin{tabular}{lcc}
\hline \multirow{2}{*}{ Impurity element } & \multicolumn{2}{c}{ Impurity element content } \\
\cline { 2 - 3 } & wt.\% & at.\% \\
\hline $\mathrm{C}$ & 3.28 & 4.35 \\
$\mathrm{O}$ & 94.64 & 94.39 \\
$\mathrm{Na}$ & 0.32 & 0.22 \\
$\mathrm{Al}$ & 1.55 & 0.92 \\
$\mathrm{Si}$ & 0.21 & 0.12 \\
Total & 100.00 & - \\
\hline
\end{tabular}

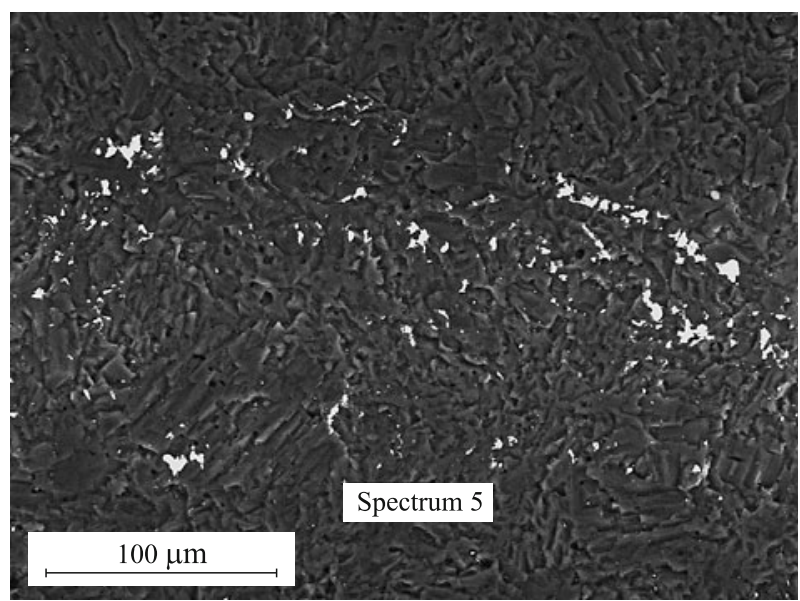

Fig. 7. Impurity phase inclusions not exhibiting high electrical conductivity in third type $\mathrm{BeO}$-ceramic.

uniformly cover ceramic surface, but also be introduced into its volume, and also be concentrated within certain areas of objects forming colored phases in the visible range of the spectrum.

Previously it has been reported that visual coloring of $\mathrm{BeO}$-ceramic differs with respect to electrophysical properties (values of dielectric permittivity $\varepsilon$ and $\operatorname{tg} \beta$ ) [15]. It has been established that value of dielectric permittivity for white, gray, and dark color plates of $\mathrm{BeO}$-ceramic varied within the range from 6.79 to 7.17 , and $\operatorname{tg} \beta$ from $5 \times 10^{-4}$ to $17 \times 10^{-4}$. For a specimen with a solid dark color the value of $\operatorname{tg} \beta$ was within the limits $25 \times 10^{-4}-6 \times 10^{-3}$. From this it follows that visually different coloring of $\mathrm{BeO}$-ceramic is characterized by difference in value of $\varepsilon$ and $\operatorname{tg} \beta$, and this affects its use in high-current electronic technology of the UHF-range.

We have attempted to study the phase composition of $\mathrm{BeO}-$ ceramic color zones by different methods [13-15]. The surface of specimens of light and colored areas has been studied in a Van-Der-Graaf accelerator with fluxes $-\mathrm{H}^{+}$with energy of $600 \mathrm{kV}$. As a result of studies presence of impurity elements $\mathrm{Si}, \mathrm{S}, \mathrm{Ca}, \mathrm{Fe}, \mathrm{Na}$, and $\mathrm{Al}$ has been established qualitatively at the surface and within the surface region of $\mathrm{BeO}$-ceramic.

As follows from Table 1, the greatest amount of impurities in $\mathrm{BeO}$-ceramic is iron, and therefore a study of the condition of iron impurities in ceramic is of particular importance. The effect of iron phase impurities on physicochemical properties has been studied by us in [1,13-16]. In order to improve mechanical property indices for objects and prepare long objects made from $\mathrm{BeO}$-ceramic they are sintered in high-temperature furnaces with graphite heaters, and also in a graphite assembly or charge, and this leads to appearance interphase boundaries and zonal coloring. Results are provided in [1] for a study of reasons for nonuniform microstructure and appearance of zonal coloring (white, gray, and dark color) in industrial objects made of BeO-ceramic. It has been established that nonuniform grain size for the micro- 
structure through the cross section of an object, affecting physicomechanical and operating properties, is connected with iron impurities, and also other impurities. The average size of $\mathrm{BeO}$ microcrystals in the same ceramic objects in zones colored gray and dark, exceeds by a factor of $1.5-3.5$ the size of microcrystals in white zones [1].

EPR and optical absorption have been used to study the physical state of iron impurities in $\mathrm{BeO}$-ceramic. It has been established [6] that occurrence of zonal coloring and grains of increased size in ceramic objects is caused predominantly by inclusions of $\mathrm{Fe}^{3+}$ ions with the $\mathrm{BeO}$ crystal lattice and appearance of surface formations on $\mathrm{BeO}$ microcrystals. EPR data have demonstrated presence in gray and dark-gray specimens of a superparamagnetic phase with strong volumetric reaction $\mathrm{Fe}^{3+}-\mathrm{Fe}^{3+}$, and probably clusters of $\mathrm{Fe}^{3+}-\mathrm{O}^{2-}-\mathrm{Fe}^{3+}$ and $\mathrm{Fe}^{3+}-\mathrm{O}^{2-}-\mathrm{Fe}^{2+}$ of different size $[1,13]$.

The method of magnetic susceptibility $\chi$ in [14] has been used to study phase formation of ferromagnetic impurities in $\mathrm{BeO}$-ceramic. In specimens cut from visually white and gray areas of the same object, at room temperature a field dependence $\chi(\mathrm{H})$ has been observed, indicating presence of ferromagnetic impurities, probably in the form of $\gamma-\mathrm{Fe}_{2} \mathrm{O}_{3}, \mathrm{Fe}_{3} \mathrm{O}_{4}$, or their solid solutions. The amount of ferromagnetic phase in specimens of visually white color was significantly less than gray color. From analysis of features of the temperature dependence of $\chi$, measured in a vacuum and in an inert gas atmosphere in ceramic specimens having a white color in the visible range of the spectrum, apart from ferromagnetic oxides $\left(\gamma-\mathrm{Fe}_{2} \mathrm{O}_{3}, \mathrm{Fe}_{3} \mathrm{O}_{4}\right)$, some amount of reduced iron metal was recorded, and this was oxidized on heating ceramic in a rough vacuum $\left(\sim 1 \times 10^{-1} \mathrm{~mm} \mathrm{Hg}\right)$ or in air after exposure at $1170 \mathrm{~K}$. In gray ceramic the amount of iron metal was significantly less than in white ceramic $[1,14,15]$.

It has been established by the NGR method that in white specimens the overall iron impurity content is less than in gray and dark specimens [16]. Iron impurity within them is predominantly in the form of $\mathrm{Fe}_{2} \mathrm{O}_{3}$ and $\mathrm{Fe}_{3} \mathrm{O}_{4}$, or as $\mathrm{Fe}_{\text {met }}$. NGR and EPR data indicate iron ions in ceramic may be in different valency states $\left(\mathrm{Fe}^{3+}\right.$ or $\left.\mathrm{Fe}^{2+}\right)$. Specimens of ceramic with gray color have an increased amount of ferromagnetic and superparamagnetic iron (probably partly in the form of clusters of $\mathrm{Fe}-\mathrm{O}-\mathrm{Fe}$ type). An increase in dark color intensity in $\mathrm{BeO}$-ceramic specimens correlates with an increase in nonmagnetic structures. Some amount of iron may form complex compounds $\mathrm{Be}_{m} \mathrm{Fe}_{n} \mathrm{O}, \mathrm{Be}_{m} \mathrm{Fe}_{n} \mathrm{OC}, \mathrm{Be}_{m} \mathrm{Fe}_{n} \mathrm{C}$, and $\mathrm{Be}_{m} \mathrm{Fe}_{n}$, and also be in the form of $\mathrm{FeO}$. In gray and dark specimens ferromagnetic structure of the $\mathrm{Fe}_{3} \mathrm{C}$ type is present (in quite a considerable amount). In gray, dark specimens, and dark films, covering $\mathrm{BeO}$-ceramic, iron carbide $\mathrm{Fe}_{3} \mathrm{C}$ has been detected, and also phases of variable composition, i.e., iron oxycarbides $\mathrm{Fe}_{x} \mathrm{O}_{y} \mathrm{C}_{z}$, whose formation is promoted by a considerable amount of carbon impurity. A change in intensity of visually dark color in specimens of ceramic correlates with an increase in nonmagnetic structures of the types $\mathrm{Be}(\mathrm{Fe}) \mathrm{O}, \mathrm{Be}(\mathrm{Fe}), \mathrm{FeBe}_{x}, \mathrm{Fe}(\mathrm{C})$, and possible $\mathrm{Fe}_{x} \mathrm{O}_{y} \mathrm{C}_{z}$. Occurrence of these structures depends on the total amount of iron and carbon in ceramic specimens, and is also connected with sintering thermodynamic conditions, as a result of which iron forms solid solutions and compounds with beryllium and carbon.

Thus, EPR, magnetic susceptibility, and NGR data indicate that iron impurities are always within the composition of $\mathrm{BeO}$-ceramic in a small or relatively large quantity. During sintering in a reducing atmosphere at high temperature they may be reduced, and also react with other impurities $(\mathrm{C}, \mathrm{Ca}$, $\mathrm{Si}, \mathrm{Al}$ ), present within ceramic and form impurity phases of complex composition, whose structure it has not yet been possible to determine.

A study of the overall composition of $\mathrm{BeO}$-ceramic by an $\mathrm{x}$-ray electron method has shown that for ceramic of white, dark, and gray color there is typically presence at the surface of sodium, silicon, aluminum, and chlorine impurities $[1,11]$. With respect to value of bond energy it may be suggested that silicon may be present in the form of dioxide, and also probably sodium silicate. Impurity Al apparently occurs at the surface of specimens during production processes for preparing $\mathrm{BeO}$ powder and operations of "burning-off an organic binder" from a ceramic with $\mathrm{Al}_{2} \mathrm{O}_{3}$ powder charge partly absorbing organic binder decomposition products. With respect to bond energy of electron level Al2p $(74.2-74.4 \mathrm{eV})$ it has been established that aluminum at the surface of BeO-ceramic specimens may be in the form of

TABLE 8. Impurity Composition and Content in Second Type BeO-Ceramic Specimen in an Area Exhibiting High Electrical Conductivity

\begin{tabular}{lcc}
\hline \multirow{2}{*}{ Impurity element } & \multicolumn{2}{c}{ Impurity element content } \\
\cline { 2 - 3 } & wt.\% & at. $\%$ \\
\hline $\mathrm{C}$ & 2.08 & 4.26 \\
$\mathrm{O}$ & 46.70 & 71.75 \\
$\mathrm{Mg}$ & 0.29 & 0.29 \\
$\mathrm{Al}$ & 2.26 & 2.06 \\
$\mathrm{Cr}$ & 6.7 & 3.17 \\
$\mathrm{Fe}$ & 41.97 & 18.47 \\
Total & 100.00 & - \\
\hline
\end{tabular}

TABLE 9. Impurity Composition and Content in Third Type BeOCeramic Specimen in an Impure Area Not Exhibiting High Electrical Conductivity

\begin{tabular}{lcc}
\hline \multirow{2}{*}{ Impurity element } & \multicolumn{2}{c}{ Impurity element content } \\
\cline { 2 - 3 } & wt.\% & at.\% \\
\hline $\mathrm{C}$ & 1.32 & 1.77 \\
$\mathrm{O}$ & 95.83 & 96.66 \\
$\mathrm{Al}$ & 1.99 & 1.19 \\
$\mathrm{P}$ & 0.28 & 0.15 \\
$\mathrm{Ca}$ & 0.57 & 0.23 \\
Total & 100.00 & - \\
\hline
\end{tabular}


$\mathrm{Al}_{2} \mathrm{O}_{3}$ and probably chrysoberyl $\mathrm{BeAl}_{2} \mathrm{O}_{4}$. In addition, at the surface of colored zones we have recorded impurities $\mathrm{Mn}, \mathrm{P}$, and Cr. Previous studies have shown [19] that chromium impurity is absorbed at the surface of $\mathrm{BeO}$-ceramic during sintering from the body of vacuum high-temperature furnace, within whose stainless steel there is chromium. Chromium reacts with $\mathrm{BeO}$ with formation of a compounds $\mathrm{BeCr}_{2} \mathrm{O}_{4}$ colored dark green.

\section{CONCLUSION}

As a result of research by means of scanning electron microscopy and an electron probe for zones of $\mathrm{BeO}$-ceramic visually colored differently presence ahs been established at the surface of impurity elements $\mathrm{Mg}, \mathrm{Na}, \mathrm{Si}, \mathrm{S}, \mathrm{Ca}, \mathrm{Fe}, \mathrm{Zn}$, $\mathrm{Al}$, and $\mathrm{Cl}$. In all ceramic specimens carbon is present as an impurity, whose content may vary. It has been established that for ceramic of three types in reflected electrons there are inclusions of impurity phases having a light color, which is confirmed by their electrical conductivity. Presence of white color in reflected electrons primarily may be connected with increased concentration of iron and carbon impurities, exhibiting high electrical conductivity (see Figs. 1-3, 6, Tables 2, 4,5 and 8). On the basis of studies performed previously for magnetic susceptibility and NGR it is possible to suggest that electrically conducting phases in specimens of three types of ceramic is caused primarily by iron impurities, present in a metal condition or in the from of iron and carbon compounds that conduct and electric current well. This is also confirmed by analysis of the oxygen content in specimens. As follows from Tables 2, 4, 5, and 8, with an increase in iron content in areas of ceramic with increased electrical conductivity the amount of oxygen is reduced to minimum values, and this points to presence of iron in a strongly reduced condition. In areas not exhibiting high electrical conductivity in secondary electrons, there is an increased content of silicon, aluminum impurities, sometimes calcium, and also probably some amount of iron whose content is difficult to determine by an x-ray spectral method.

An increase in color intensity in reflected electrons of impurity phases of dark color in specimens of $\mathrm{BeO}$-ceramic correlates with an increase in their impurities, contained within the composition of silicon, aluminum compounds, and probably iron, not exhibiting high electrical conductivity, whose formation is promoted by some amount carbon impurity. As there is a reduction in impurity concentration of reduced iron phases, and an increase in aluminum and silicon impurities the color of zones in secondary electrons acquires a pale white and dark color, which points to a reduction in electrical conductivity of these zones.

In BeO-ceramic specimens of the third type, where colored spots are observed in gray ceramic, within in impurity phases there is predominance of aluminum impurity, probably in the form of $\mathrm{Al}_{2} \mathrm{O}_{3}$.

\section{REFERENCES}

1. V. S. Kiiko, Yu. N. Makurin, and A. L. Ivanovskii, Ceramics Based on Beryllium Oxide: Preparation and Physicochemical Properties and Applications [in Russian], URO RAN, Ekaterinburg (2006).

2. R. A. Belayaev, Beryllium Oxide [in Russian], Atomizdat, Moscow (1980).

3. V. S. Kiiko, I. A. Dmitriev, Yu. N. Makurin, et al., "Preparation and application of transparent beryllium ceramic," Fiz. Khim. Stekla, 30(1), 149 - 151 (2004).

4. G. P. Akishin, S. K. Turnaev, V. Ya. Vaispapir, et al., "Composition of beryllium oxide ceramics," Refr. Industr. Ceram., 51(5), $377-381$ (2010).

5. V. S. Kiiko, "Transparent beryllia ceramics for laser technology and ionizing radiation dosimetry," Refr. Industr. Ceram., 45(4), $266-272$ (2004).

6. V. S. Kiiko, S. N. Shabunin, and Yu. N. Makurin, "Preparation and physiochemical properties and transmission of UHF-radiation by ceramic based on BeO," Ogneupory Tekhn. Keram., No. 10, 8 - 17 (2004).

7. Yu. N. Makurin, V. S. Kiiko, I. R. Shein, et al., "Single crystals and light-transmitting BeO-ceramic for electronic technology," Refr. Industr. Ceram., 51(3), 167 - 171 (2010).

8. V. S. Kiiko, "Electrophysical properties of beryllia ceramic with impurities," in: Refractories at the Boundary of Centuries (XX-XXI) [in Russian], UrGU, Ekaterinburg (2001).

9. M. A. Gorbunova, I. R. Shein, V. S. Kiiko, et al. "Electronic and magnetic properties of beryllium oxide with $3 d$ impurities from first-principles calculations," Physica, B400, 47 - 52 (2008).

10. I. R. Shein, M. A. Gorbunova, Yu. N. Makurin, et al., "Effect of S, P, D impurities and structural vacancies on electronic and magnetic properties of beryllium monoxide," Proc. Internat. STC "Physicochemical processes in inorganic materials (FPKh-10)," Kemerovo, October (2007).

11. V. S. Kiiko, Yu. N. Makurin, and V. F. Balakirov, "Composition and properties of industrial ceramics based on beryllium oxide," Khim. Tekhnol., No. 1, 7 - 14 (2004).

12. V. S. Kiikoo, I. A. Dmitriev, Yu. M. Makurin, et al., "Surface of powders and beryllia ceramic, in: Refractories at the Boundary of Centuries $(X X-X X I)$ [in Russian], UrGU, Ekaterinburg (2001).

13. V. S. Kiiko, I. A. Dmitriev, and I. D. Kashcheev, "Reasons for beryllia ceramic coloring," Neorgan. Materialy, 27(9), 1945 - 1947 (1991).

14. V. S. Kiiko, I. I. Piratinskaya, and Yu. A. Vershchagin, "Effect of iron impurity on beryllium ceramic coloring," Neorgan. Materialy, 28(8), 1786 - 1791 (1992).

15. V. S. Kiiko, V. Ya. Vaispapir, M. A. Gorbunova, et al., "Effect of iron impurity phases on color and electrophysical properties of beryllia ceramic," Ogneupory Tekhn. Keram. No. 9, 8-12 (2006).

16. V. A. Shabashov, V. S. Kiiko, I. A. Dmitriev, et al., "The state of iron impurities in a beryllia ceramic as determined from NGRS data," Ceram. Int., 30(1), 1 - 7 (2004).

17. V. S. Kiiko, M. A. Gorbunova, Yu. N. Makurin, et al., "Microstructure and electric conductivity of composite $\left(\mathrm{BeO}+\mathrm{TiO}_{2}\right)$ ceramics," Refr. Industr. Ceram., 48(6), 429 - 434 (2007).

18. M. V. Kuznetsov, V. S. Kiiko, and A. L. Ivanovksii, "X-ray photoelectron spectroscopy of complex ceramic oxide: BeO-TiO 2 -C," Steklo. Keram., No. 10, 16 - 21 (2010).

19. V. S. Kiiko, Yu. N. Makurin, I. A. Dmitriev, et al., "Formation of beryllium chromate under different thermodynamic conditions," Proc. Conf. "Solid chemistry and functional materials," IKhTT UrO RAN, Ekaterinburg (2004). 